\title{
Pulmonary capillary hemangiomatosis: a focus on the EIF2AK4 mutation in onset and pathogenesis
}

\author{
This article was published in the following Dove Press journal: \\ The Application of Clinical Genetics \\ 7 August 2015 \\ Number of times this article has been viewed
}

\author{
Lijiang Ma ${ }^{1, *}$ \\ Ruijun $\mathrm{Bao}^{2, *}$ \\ 'Department of Pediatrics and \\ Medicine, Division of Molecular \\ Genetics, Columbia University \\ Medical Center, New York, NY, ${ }^{2}$ The \\ Children's IBD Center, Mount Sinai \\ Hospital, New York, NY, USA \\ *These authors contributed equally to \\ this work
}

\begin{abstract}
Pulmonary capillary hemangiomatosis $(\mathrm{PCH})$ is a pulmonary vascular disease that mainly affects small capillaries in the lung, and is often misdiagnosed as pulmonary arterial hypertension or pulmonary veno-occlusive disease due to similarities in their clinical presentations, prognosis, and management. In patients who are symptomatic, there is a high mortality rate with median survival of 3 years after diagnosis. Both idiopathic and familial PCH cases are being reported, indicating there is genetic component in disease etiology. Mutations in the eukaryotic translation initiation factor $2 \alpha$ kinase 4 (EIF2AK4) gene were identified in familial and idiopathic $\mathrm{PCH}$ cases, suggesting EIF2AK4 is a genetic risk factor for PCH. EIF $2 A K 4$ mutations were identified in $100 \%(6 / 6)$ of autosomal recessively inherited familial $\mathrm{PCH}$ and $20 \%(2 / 10)$ of sporadic PCH cases. EIF2AK4 is a member of serine/threonine kinases. It downregulates protein synthesis in response to a variety of cellular stress such as hypoxia, viral infection, and amino acid deprivation. Bone morphogenetic protein receptor 2 (BMPR2) is a major genetic risk factor in pulmonary arterial hypertension and EIF2AK4 potentially connects with BMPR2 to cause PCH. L-Arginine is substrate of nitric oxide synthase, and L-arginine is depleted during the production of nitric oxide, which may activate EIF2AK4 to inhibit protein synthesis and negatively regulate vasculogenesis. Mammalian target of rapamycin and EIF2 $\alpha$ kinase are two major pathways for translational regulation. Mutant EIF $2 A K 4$ could promote proliferation of small pulmonary arteries by crosstalk with mammalian targets of the rapamycin signaling pathway. EIF2AK4 may regulate angiogenesis by modulating the immune system in $\mathrm{PCH}$ pathogenesis. The mechanisms of abnormal capillary angiogenesis are suggested to be similar to that of tumor vascularization. Specific therapies were developed according to pathogenesis and are proved to be effective in reported cases. Targeting the EIF2AK4 pathway may provide a novel therapy for $\mathrm{PCH}$.
\end{abstract}

Keywords: EIF2AK4, genetics, pulmonary arterial hypertension, pulmonary veno-occlusive disease

\section{Introduction}

Pulmonary capillary hemangiomatosis $(\mathrm{PCH})$ is a devastating disease characterized by dysregulated pulmonary capillary angiogenesis infiltrating peribronchial, perivascular interstitium, and lung parenchyma. According to the Fifth World Symposium on Pulmonary Hypertension held in Nice, $\mathrm{PCH}$, together with pulmonary veno-occlusive disease (PVOD), is classified as a subcategory of group 1 pulmonary arterial hypertension (PAH). ${ }^{1}$

PCH was first described in 1978. The case was characterized by invasive abnormal angiomatous growth in pulmonary intralobular fibrous septa that destroyed and
Correspondence: Lijiang Ma

Department of Pediatrics and Medicine, Division of Molecular Genetics, Columbia University Medical Center, II 50 St. Nicholas Ave, New York, NY 10032 , USA

$\mathrm{Tel}+|21285| 5318$

Fax + I 21285I 5306

Email Im2689@columbia.edu 
obstructed pulmonary veins and venules. ${ }^{2}$ The disease has been recognized since then, and several cases have been reported. ${ }^{3-5}$ Frequent clinical presentations are dyspnea, hemoptysis, fever, pleural effusions, and crackles on lung auscultation. ${ }^{6}$ Chest X-ray, computerized tomography scan of chest, pulmonary function tests, and pulmonary angiography are performed in patients when $\mathrm{PCH}$ is suspected. Definite diagnosis is made by biopsy, autopsy, or examination of lung explants. In a small number of reported cases, histopathological features of $\mathrm{PCH}$ overlapped with PAH and PVOD, as well as some other diseases, such as pulmonary fibrosis, pulmonary embolism, pulmonary hemosiderosis, arteriovenous malformation, lymphangiectasia, and hemangioendotheliomatosis. ${ }^{6,7}$ The characters of primary $\mathrm{PAH}, \mathrm{PVOD}$, and $\mathrm{PCH}$ cases are listed in Table 1 for comparison. ${ }^{8-19}$ Symptomatic $\mathrm{PCH}$ cases are rare occurrences, with approximately only 100 cases reported before $2011 .{ }^{20}$

The etiology of $\mathrm{PCH}$ is currently unknown. It is proposed that $\mathrm{PCH}$ is an angiogenic disease. Angiogenic factors such as platelet-derived growth factor, vascular endothelial growth factor, and angiopoietin are increased in $\mathrm{PCH}$, which are responsible for the pathological growth of capillary blood vessels, while angiogenic factors are usually tightly regulated so that neovascularization is not occurring in the normal situation. ${ }^{21-25}$ On the contrary, histopathology examination indicated that endothelial cells that comprise $\mathrm{PCH}$ lesions are cytologically bland and show no mitotic activity. ${ }^{25} \mathrm{PCH}$ usually occurs diffusely in both lungs with or without PAH development. ${ }^{26-29}$ In some instances, solitary nodules or focal PCH-like lesions have been found in lung periphery in patients who had no clinical symptoms of the disease. This constitutes $5.7 \%$ of autopsies examined. ${ }^{30,31}$ In these cases, subjects are male dominant (nine males and one female) with an average age of 65 years, indicating that there is a different etiology for this subgroup of patients. It has been reported that PCH can occur in association with cardiomyopathy, ${ }^{32}$ aortic stenosis, ${ }^{33}$ Kartagener syndrome, ${ }^{34}$ congenital diaphragmatic hernia, ${ }^{35}$ connective tissue diseases such as systemic lupus erythematosus, and scleroderma, ${ }^{36-38}$ Takayasu's arteritis, ${ }^{39}$ and cancer. ${ }^{40,41}$ Recurrence of $\mathrm{PCH}$ after bilateral lung transplantation was reported, suggesting that there is an infectious or inflammatory cause inciting uncontrolled angiogenesis. ${ }^{42,43}$ The etiology of PCH may be genetic: both sporadic and familial PCH cases have been observed. Most familial $\mathrm{PCH}$ cases are autosomal recessively inherited, but autosomal dominant inheritance has also been reported. ${ }^{13,44,45}$

\section{EIF2AK4 as a novel genetic cause of $\mathrm{PCH}$}

Eukaryotic translation initiation factor $2 \alpha$ kinase 4 (EIF2AK4) is presented in all eukaryotes from yeast to mammals and plays an important role in the transcriptional regulation. ${ }^{46}$ Using whole exome sequencing, novel mutations in EIF2AK4 gene were identified in familial PCH case patients. In one family, both affected brothers had compound heterozygous mutations, c.1153dupG (p.Val385fs) and c.3766C $>$ T (p.Arg1256X), in EIF2AK4. Unaffected parents were heterozygous carriers of one of the two mutations (the mother carried the frameshift mutation, c.1153dupG, and the father carried the nonsense mutation, c. $3766 \mathrm{C}>\mathrm{T}){ }^{13}$ Ten additional sporadic $\mathrm{PCH}$ case patients were screened for EIF2AK4 mutations by Sanger sequencing. A homozygous frameshift mutation c.1392delT (p.Arg465fs) was found in one subject. Another patient had a compound heterozygous splice mutation (c.860-1G $>$ A) and a nonsense mutation, c.3438C $>\mathrm{T}$ (p.Arg1150X). No mutations were identified in this gene in one autosomal-dominant familial PCH case. All subjects recruited in the study were histologically confirmed to have $\mathrm{PCH} .{ }^{13}$ There are a total of five mutations identified in EIF2AK4 gene in $\mathrm{PCH}$ patients. Mutations occurred in one autosomal recessively inherited familial PCH case but no mutation was found in an autosomal dominantly inherited familial PCH case. EIF2AK4 mutations occurred in $20 \%(2 / 10)$ sporadic PCH cases. ${ }^{13}$ Patients who have the same mutations in EIF2AK4 had different age of onset and different severity of the disease. ${ }^{13}$ This suggests that additional genetic and/or environmental factors may modify the onset and severity of $\mathrm{PCH}$ in association with EIF2AK4 mutations.

EIF2AK4 is a member of serine/threonine kinases that downregulates protein synthesis in response to a variety of cellular stress and amino acid deprivation. EIF2AK4, also called general control nondepressible-2 (GCN2), is activated by amino acid deprivation, viral infection, proteasome inhibition, and hypoxia. ${ }^{46}$ EIF2AK4 has 1,649 amino acids, encoding RWD (RING finger-containing proteins, WD-repeat-containing proteins, and yeast DEAD [DEXD]like helicases) domain, pseudokinase domain, protein kinase domain, and histidyl-tRNA synthetase (HisRS)related domain. Expression of EIF2AK4 can be found in all human tissues, including lung and aorta endothelial cells. ${ }^{47}$ Immunohistochemistry indicated that EIF2AK4 is expressed in smooth muscle cells in small pulmonary venules. There is a diffuse interstitial staining. Macrophages and some mononuclear cells are positive for staining but endothelial cells are negative for EIF2AK4 in pulmonary veins. ${ }^{15}$ EIF2AK4 expression was not detected in PVOD mutant lungs. In PCH 


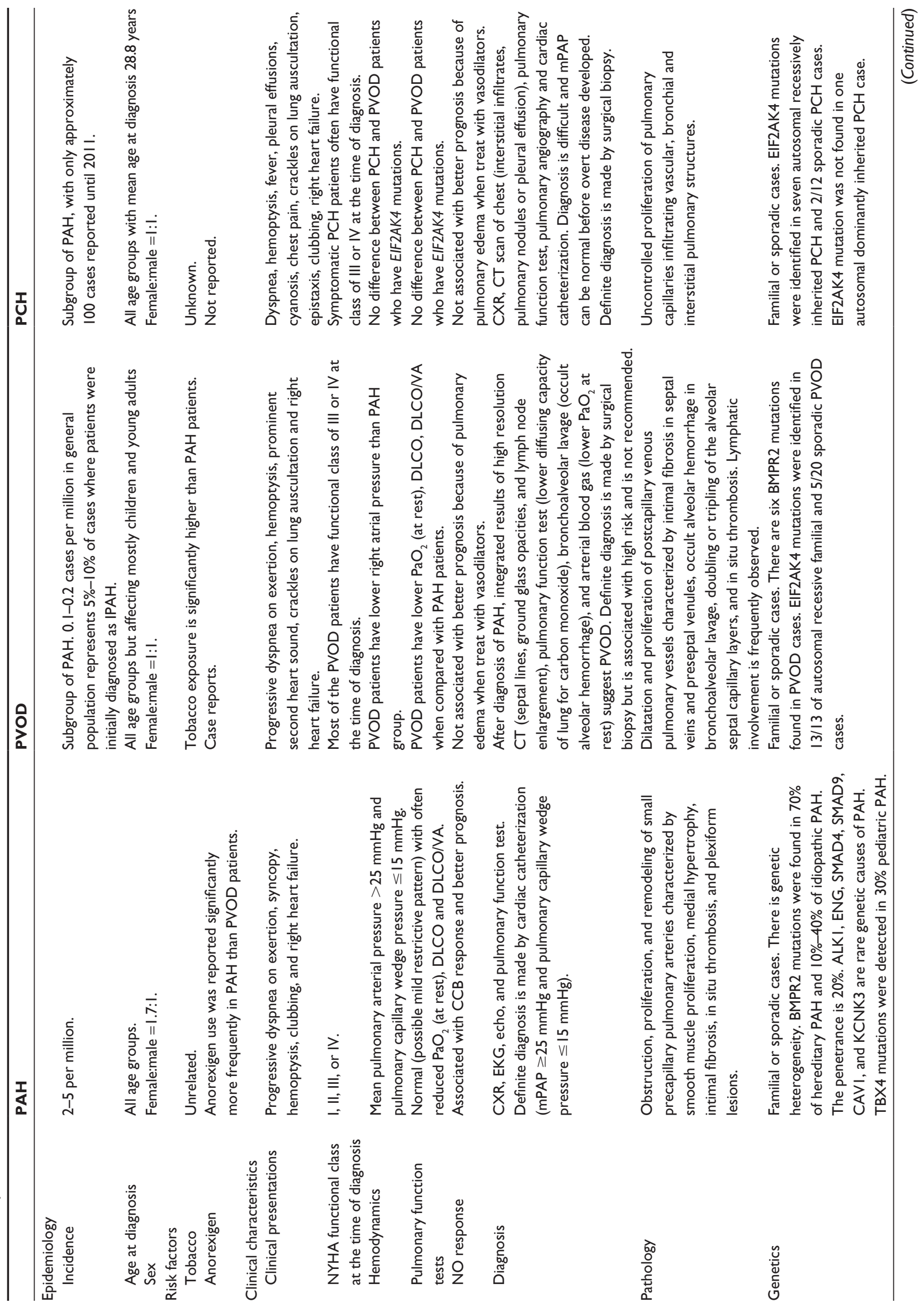




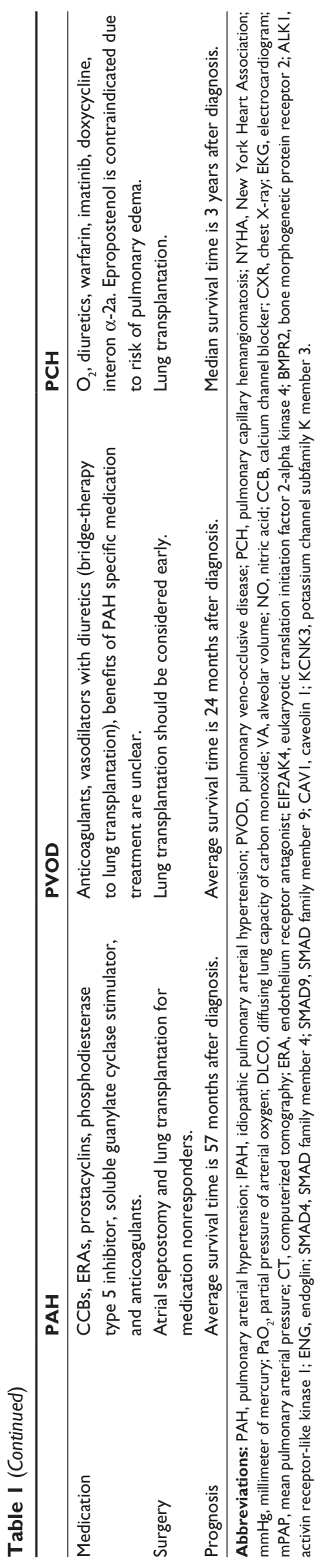

patients, how EIF2AK4 regulates pulmonary angiogenesis and whether EIF2AK4 mutations identified in these patients are gain- or loss-of-function are not clear at this point.

\section{EIF2AK4 and bone morphogenetic protein}

Why EIF2AK4 mutation could cause abnormal angiogenesis in lungs in PCH patients remains unknown. EIF2AK4-knockout mice were generated. ${ }^{48,49}$ Mutant mice are viable, fertile, and exhibit no phenotypic abnormalities under standard growth conditions. The lungs of these mutant mice have not been examined. In coping with stress, EIF2AK4 decreases global protein synthesis, increasing specific mRNA synthesis for transcription factors and enabling cells to initiate a survival response to the initial activating cue. ${ }^{50} \mathrm{EIF} 2 \mathrm{AK} 4$ may regulate bone morphogenetic protein receptor 2(BMPR2)-transforming growth factor-beta pathway, which is known to be the genetic cause of PAH. It is reported that EIF2AK4 binds with mothers against decapentaplegic drosophila homolog of 4 (SMAD family member 4) and transforming growth factor-beta receptor 1 in human embryonic kidney cells to regulate the epithelial-mesenchymal transition..$^{51}$ EIF2AK4 regulates activating transcription factor 4 (ATF4), which transcriptionally regulates the Tribbles homolog 3..$^{52,53}$ In human primary pulmonary artery smooth muscle cells, Tribbles-like protein 3 interacts with BMPR2 on the cell surface through BMPR2 tail domain. ${ }^{54}$ Further studies are needed to investigate whether EIF2AK4 interplays with bone morphogenetic protein signaling in pulmonary blood vessels and if mutations in EIF2AK4 could cause BMPR2 haploinsufficiency in $\mathrm{PCH}$.

\section{EIF2AK4 and nitric oxide synthase}

EIF2AK4 is activated by amino acid depletion. L-arginine is a substrate of nitric oxide synthase (NOS), and L-arginine will be depleted during the production of nitric oxide. Study indicated that the depletion of L-arginine will activate EIF2AK4. ${ }^{55}$ EIF2AK4 will downregulate protein synthesis on activation. In mouse skin, NOS mediates ultraviolet light-induced EIF $2 \alpha$ phosphorylation by activation of both PERK and EIF2AK4 via oxidative stress and L-arginine starvation signaling pathways. ${ }^{56}$ In human, there are three types of NOSs, including neuronal, inducible, and endothelial NOS. Endothelial NOS (eNOS) is expressed in pulmonary vascular endothelium and is involved in PAH pathogenesis. ${ }^{57}$ An animal study indicated that there are microvascular endothelial progenitor cells in pulmonary arteries. These cells express eNOS and possess vasculogenic capacity while maintaining functional endothelial microvascular specificity. ${ }^{58}$ It is possible that 
EIF2AK4 activation can be induced by L-arginine depletion due to eNOS activity, and EIF2AK4 prevents abnormal vasculogenesis. It will be informative to investigate if EIF2AK4 inactivation could affect homeostasis of angiogenesis through eNOS in PCH lungs.

\section{EIF2AK4 and mammalian target of rapamycin}

Target of rapamycin (TOR) and EIF2 $\alpha$ kinase are the two major pathways for translational regulation. These two signal transduction pathways react to amino acid deprivation by inhibiting general protein translation, while at the same time, increasing translation of specific mRNAs involved in restoring homeostasis. EIF2AK4 senses the absence of one or more amino acids by virtue of direct binding to the uncharged tRNAs. The presence of certain amino acids, such as leucine, permits activation of the master growth regulating kinase TOR. ${ }^{59}$ Studies from yeast and mammals indicate that EIF2AK4 and TOR pathways are interlinked, and the crosstalk between the two pathways varies with the actual stress applied. ${ }^{60,61}$ Mammalian TOR (mTOR) is a downstream effector of the phosphatidylinositol 3-kinase/Akt, and mTOR regulates ribosomal p70 S6 kinase (S6K1) and the mRNA cap-binding protein inhibitory protein, 4E-BP1 in response to stimuli. ${ }^{62}$ EIF2AK4 contributes to the regulation of 4E-BP1 and $\mathrm{S} 6 \mathrm{~K} 1$ in response to leucine depletion in EIF2AK4knockout mice. ${ }^{49}$ Evidence suggested the critical role of mTOR in remodeling small pulmonary arteries and PAH. mTOR increases proliferation and cell survival in chronic hypoxia, and the inhibition of mTOR activity may provide a novel treatment for PAH patients. ${ }^{63,64}$

It is possible that the loss of EIF2AK4 could promote proliferation of small pulmonary arteries by crosstalk with mTOR signaling pathway.

\section{EIF2AK4 and immune system}

Macrophages and neutrophils are involved in angiogenesis in lung tumor formation. ${ }^{65}$ Studies indicated that increased inflammation, such as pulmonary infiltration of macrophages, is one of the pathologic phenotypes in PAH. ${ }^{66}$ EIF2AK4 expression was observed in macrophages and in some mononuclear cells in lungs. ${ }^{15}$ This suggested that EIF2AK4 may regulate angiogenesis by modulating the immune system in $\mathrm{PCH}$ pathogenesis. Mutations in EIF2AK4 may inactivate macrophages and reduce cytokine production and immune response. This is proved by an animal study. ${ }^{67} \mathrm{~A}$ recessive loss-of-function mutation in $E I F 2 A K 4$ mutant mouse strain was isolated by screening macrophage's susceptibility to virus infection. EIF $2 A K 4$ mutant mice showed innate immune defect and modest increase in susceptibility to DNA viruses' mouse cytomegalovirus infection. ${ }^{67}$ Furthermore, macrophage is one of the immune cell types that produces $\alpha$-interferon, and interferon- $2 \alpha$ has been applied in PCH treatment successfully. ${ }^{68}$

\section{EIF2AK4 and tumor}

In response to stress, EIF2AK4 induces phosphorylation of the alpha $(\alpha)$ subunit of the translation initiation factor eIF2 at serine 51 (eIF2 $\alpha \mathrm{S} 51 \mathrm{P})$, and the latter plays an essential role in stress-induced tumorigenesis. ${ }^{69}$ Evidence suggested that EIF2AK4-eIF2 $\alpha$-ATF4 pathway regulates mitochondrial phosphoenolpyruvate carboxykinase (PEPCK-M), which is presented in tumor of several origins and played an important role in cancer metabolism. ${ }^{70}$ EIF2AK4-eIF2alpha-ATF4 pathway is critical for maintaining metabolic homeostasis (such as oxygen and nutrient) in tumor cells and is a potential target for tumor therapy. ${ }^{71,72}$ In human tumors, EIF2AK4/ATF4 regulates tumor growth and angiogenesis through amino acid deficiency-mediated vascular endothelial growth factor. ${ }^{73}$ It is possible that EIF2AK4 regulates vascular growth in $\mathrm{PCH}$ through similar mechanisms observed in tumor.

\section{Correlate PCH case pathogenesis with diagnosis and treat}

EIF 2AK4 mutations were found in some subjects in both $\mathrm{PCH}$ and PVOD groups, indicating that these two diseases could not be differentiated by genetic testing. Clinical data were collected from previously reported $\mathrm{PCH}$ case and PVOD patients who carried EIF2AK4 mutations. ${ }^{13-15}$ Clinical features of patients who had mutations in EIF $2 A K 4$ in PCH cases and PVOD were compared. Results indicated that there is male predominance (three males and one female) in PCH cases when compared with PVOD (13 males and 13 females) but the difference is not statistically significant (Table 2). This indicated that the pathogenesis of PCH and PVOD might be distinct. There is no difference in other characters including age at diagnosis, mean pulmonary arterial pressure, pulmonary capillary wedge pressure, diffusing capacity of the lung for carbon monoxide (DLCO), and ratio of number of patients who had lung transplantation versus no lung transplantation between these two groups (Table 2). When pulmonary function variables were compared between PAH and EIF $2 A K 4$ mutant PVOD patients, significantly reduced DLCO and increased ventilator demand to cardiopulmonary exercise testing in PVOD group were observed. ${ }^{19,74}$ These studies are helpful for the identification of disease mechanisms and genotype phenotype correlations. BMPR2 mutations have 
been identified in 70\% of heritable PAH and $10 \%-40 \%$ of idiopathic PAH. Six BMPR2 mutations were reported in PVOD patients. However, no BMPR2 mutations were found in $\mathrm{PCH}$ patients.

Treatments used for other causes of pulmonary hypertension, such as diuretics, corticosteroids, and warfarin, are also used to treat PCH. However, these drugs are relatively ineffective, and the prognosis is poor. This is probably because pathogenesis of PAH is arterialization of small pulmonary arteries, while PCH develops due to abnormal angiogenesis which occludes pulmonary veins and venules. It is also possible that PAH and PCH have different etiologies. Vasodilators such as prostacyclin therapy, a mainstay in the treatment of pulmonary hypertension, have been reported to cause sudden respiratory distress or death and have to be used cautiously in $\mathrm{PCH}$ patients. ${ }^{75}$ Platelet-derived growth factor and its receptor have been implicated in the pathogenesis of PCH. ${ }^{76}$ Imatinib, a platelet growth factor receptor antagonist, showed efficacy in PCH treatment. ${ }^{77,78}$ Doxycycline, a matrix metalloproteinase and angiogenesis inhibitor, could be a treatment option for the $\mathrm{PCH}$ patients who have elevated levels of matrix metalloproteinase and capillary proliferation. ${ }^{79}$ Interferons are cytokines secreted by host cells in response to stimuli. Interferons can inhibit proliferation and collagen synthesis, inhibit cell motility, enhance prostacyclin production, enhance phagocytic activity of macrophages, and modulate immune system. ${ }^{80-82}$ There are three main types of interferons known as alpha, beta, and gamma. ${ }^{83}$ Interferon alpha-2a has been used in the treatment of $\mathrm{PCH}$ and is effective in a few cases. ${ }^{71,84,85}$ Targeting EIF2AK4-ATF4 pathway may provide a novel therapy for $\mathrm{PCH}$ patients. ${ }^{72}$ For medication nonresponders, lung transplantation is considered as definite treatment.

Table 2 Comparison of clinical characteristics in PCH and PVOD patients with EIF2AK4 mutations

\begin{tabular}{llll}
\hline Characteristics & PCH (n=4) & PVOD (n=26) & P-value* \\
\hline Age, years, median (range) & $20.5(15,33)$ & $24.5(11,50)$ & 0.39 \\
Sex, male (\%) & $3(75 \%)$ & $13(50 \%)$ & 0.60 \\
mPAP, median (range) & $52(40,77)$ & $50.5(22,75)$ & 0.58 \\
PCWP, median (range) & $6(5,9)$ & $6.5(3,15)$ & $\mathrm{I}$ \\
DLCO, median (range) & $31(26,33)$ & $32(18,65)$ & 0.96 \\
Lung transplantation, yes (\%) & $3(75 \%)$ & $18(69.2 \%)$ & $\mathrm{I}$ \\
\hline
\end{tabular}

Notes: *R software (version 3.1.2) was used for statistical analysis. Comparisons of sex and lung transplantation variables were assessed by Fisher's exact test, and comparisons of all of the other variables were assessed by Wilcoxon signed-rank test. P-values are for two-tailed tests. A $P$-value $<0.05$ was considered to be statistically significant.

Abbreviations: $\mathrm{PCH}$, pulmonary capillary hemangiomatosis; PVOD, pulmonary veno-occlusive disease; EIF2AK4, eukaryotic translation initiation factor 2-alpha kinase 4; mPAP, mean pulmonary arterial pressure; PCWP, pulmonary capillary wedge pressure; DLCO, diffusing lung capacity of carbon monoxide.

\section{Conclusion}

$\mathrm{PCH}$ is a subgroup of PAH characterized by uncontrolled capillary proliferation in the lung. Clinically, $\mathrm{PCH}$ can be asymptomatic, develop with or without $\mathrm{PAH}$, or develop in association with other diseases. This indicated that the disease is heterogeneous. Mutations in EIF $2 A K 4$ were found in one autosomal recessively inherited PCH case and 20\% (2/10) idiopathic $\mathrm{PCH}$ case, suggesting that EIF2AK4 is a genetic risk factor for a subgroup of $\mathrm{PCH}$ patients. EIF $2 A K 4$ encodes a protein kinase that downregulates the protein synthesis in response to varied cellular stress. EIF2AK4 may interact with BMPR2, NOS, and mTOR to regulate angiogenesis. Evidence also suggested EIF2AK4 can regulate immune system in response to infection or regulate angiogenesis through similar mechanisms observed in tumor. Medications used for PAH were applied in $\mathrm{PCH}$ treatment but are relatively ineffective. Vasodilators should be used cautiously due to risk of pulmonary edema, respiratory distress, and death. Medications targeting pathogenesis of $\mathrm{PCH}$, such as imatinib, doxycycline, and interferon alpha-2a, are reported to be effective in some cases. Targeting EIF2AK4 pathway could provide a potential novel therapy for PCH. EIF2AK4 mutations were identified in a small portion of sporadic $\mathrm{PCH}$ cases, and no mutations were found in autosomal dominantly inherited PCH cases, indicating that there are other genetic factors associated with $\mathrm{PCH}$.

\section{Disclosure}

The authors report no conflicts of interest in this work.

\section{References}

1. Lau EM, Humbert M. A critical appraisal of the updated 2014 nice pulmonary hypertension classification system. Can J Cardiol. 2015;31(4): 367-374.

2. Wagenvoort CA, Beetstra A, Spijker J. Capillary haemangiomatosis of the lungs. Histopathology. 1978;2(6):401-406.

3. Whittaker JS, Pickering CA, Heath D, Smith P. Pulmonary capillary haemangiomatosis. Diagn Histopathol. 1983;6(2):77-84.

4. Magee F, Wright JL, Kay JM, Peretz D, Donevan R, Churg A. Pulmonary capillary hemangiomatosis. Am Rev Respir Dis. 1985;132(4): 922-925.

5. Faber CN, Yousem SA, Dauber JH, Griffith BP, Hardesty RL, Paradis IL. Pulmonary capillary hemangiomatosis. A report of three cases and a review of the literature. Am Rev Respir Dis. 1989;140(3):808-813.

6. Almagro P, Julià J, Sunjaume M, et al. Pulmonary capillary hemangiomatosis associated with primary pulmonary hypertension: report of 2 new cases and review of 35 cases from the literature. Medicine (Baltimore). 2002;81(6):417-424.

7. Lantuéjoul S, Sheppard MN, Corrin B, Burke MM, Nicholson AG. Pulmonary veno-occlusive disease and pulmonary capillary hemangiomatosis: a clinicopathologic study of 35 cases. Am J Surg Pathol. 2006;30(7):850-857.

8. Austin ED, Ma L, LeDuc C, et al. Whole exome sequencing to identify a novel gene (caveolin-1) associated with human pulmonary arterial hypertension. Circ Cardiovasc Genet. 2012;5(3):336-343. 
9. Ma L, Roman-Campos D, Austin ED, et al. A novel channelopathy in pulmonary arterial hypertension. $N$ Engl J Med. 2013;369(4): 351-361.

10. Ma L, Chung WK. The genetic basis of pulmonary arterial hypertension. Hum Genet. 2014;133(5):471-479.

11. Kerstjens-Frederikse WS, Bongers EM, Roofthooft MT, et al. TBX4 mutations (small patella syndrome) are associated with childhoodonset pulmonary arterial hypertension. J Med Genet. 2013;50(8): 500-506.

12. Machado RD, Aldred MA, James V, et al. Mutations of the TGF-beta type II receptor BMPR2 in pulmonary arterial hypertension. Hum Mutat. 2006;27(2):121-132.

13. Best DH, Sumner KL, Austin ED, et al. EIF2AK4 mutations in pulmonary capillary hemangiomatosis. Chest. 2014;145(2):231-236.

14. Tenorio J, Navas P, Barrios E, et al. A founder EIF2AK4 mutation causes an aggressive form of pulmonary arterial hypertension in Iberian gypsies. Clin Genet. Epub December 16, 2014.

15. Eyries M, Montani D, Girerd B, et al. EIF2AK4 mutations cause pulmonary veno-occlusive disease, a recessive form of pulmonary hypertension. Nat Genet. 2014;46(1):65-69.

16. Montani D, Achouh L, Dorfmüller P, et al. Pulmonary veno-occlusive disease: clinical, functional, radiologic, and hemodynamic characteristics and outcome of 24 cases confirmed by histology. Medicine (Baltimore). 2008;87(4):220-233.

17. Runo JR, Vnencak-Jones CL, Prince M, et al. Pulmonary veno-occlusive disease caused by an inherited mutation in bone morphogenetic protein receptor II. Am J Respir Crit Care Med. 2003;167(6):889-894.

18. Montani D, Kemp K, Dorfmuller P, Sitbon O, Simonneau G, Humbert M. Idiopathic pulmonary arterial hypertension and pulmonary venoocclusive disease: similarities and differences. Semin Respir Crit Care Med. 2009;30(4):411-420.

19. Laveneziana P, Montani D, Dorfmüller P, et al. Mechanisms of exertional dyspnoea in pulmonary veno-occlusive disease with EIF2AK4 mutations. Eur Respir J. 2014;44(4):1069-1072.

20. Langleben D. Pulmonary capillary hemangiomatosis: the puzzle takes shape. Chest. 2014;145(2):197-199.

21. Assaad AM, Kawut SM, Arcasoy SM, et al. Platelet-derived growth factor is increased in pulmonary capillary hemangiomatosis. Chest 2007;131(3):850-855.

22. Kawut SM, Assaad AM, Arcasoy SM, Rosenzweig EB, Sonett JR, Borczuk AC. Pulmonary capillary hemangiomatosis: results of gene expression analysis. Chest. 2005;128(Suppl 6):575S-576S.

23. Folkman J, Klagsbrun M. Angiogenic factors. Science. 1987;235(4787): $442-447$

24. Sakashita N, Motooka Y, Suganuma M, et al. A case of pulmonary capillary hemangiomatosis with pulmonary fibrosis associated with MMP-9 related pulmonary remodeling. Pathol Int. 2011;61(5):306-312.

25. O'Keefe MC, Post MD. Pulmonary capillary hemangiomatosis: a rare cause of pulmonary hypertension. Arch Pathol Lab Med. 2015;139(2): 274-277.

26. Ito $\mathrm{K}$, Ichiki $\mathrm{T}$, Ohi $\mathrm{K}$, et al. Pulmonary capillary hemangiomatosis with severe pulmonary hypertension. Circ J. 2003;67(9):793-795.

27. Umezu H, Naito M, Yagisawa K, Hattori A, Aizawa Y. An autopsy case of pulmonary capillary hemangiomatosis without evidence of pulmonary hypertension. Virchows Arch. 2001;439(4):586-592.

28. Cioffi U, De Simone M, Pavoni G, et al. Pulmonary capillary hemangiomatosis in an asymptomatic elderly patient. Int Surg. 1999;84(2): $168-170$.

29. Takiguchi Y, Uruma T, Hiroshima K, et al. Stable pulmonary capillary haemangiomatosis without symptomatic pulmonary hypertension. Thorax. 2001;56(10):815-817.

30. Fugo K, Matsuno Y, Okamoto K, et al. Solitary capillary hemangioma of the lung: report of 2 resected cases detected by high-resolution CT. Am J Surg Pathol. 2006;30(6):750-753.

31. Havlik DM, Massie LW, Williams WL, Crooks LA. Pulmonary capillary hemangiomatosis-like foci. An autopsy study of 8 cases. Am J Clin Pathol. 2000;113(5):655-662.
32. Jing X, Yokoi T, Nakamura Y, et al. Pulmonary capillary hemangiomatosis: a unique feature of congestive vasculopathy associated with hypertrophic cardiomyopathy. Arch Pathol Lab Med. 1998;122(1):94-96.

33. Wang KY, Tanimoto A, Inenaga $\mathrm{T}$, et al. Pulmonary capillary hemangiomatosis in chronic cardiac failure due to aortic stenosis. $J U O E H$. 2009;31(4):339-344.

34. Słodkowska J, Słupek A, Burakowski J, Bestry I, Filipecki S, Radomski P. Kartagener syndrome and hemangiomatous proliferation of lung capillaries: case report and literature review. Pneumonol Alergol Pol. 1996;64(3-4):217-224.

35. Akinkuotu AC, Sheikh F, Cass DL, et al. Pulmonary capillary hemangiomatosis in a neonate with congenital diaphragmatic hernia. Pediatr Surg Int. 2015;139(2):274-277.

36. Fernández-Alonso J, Zulueta T, Reyes-Ramirez JR, Castillo-Palma MJ, Sanchez-Román J. Pulmonary capillary hemangiomatosis as cause of pulmonary hypertension in a young woman with systemic lupus erythematosus. J Rheumatol. 1999;26(1):231-233.

37. Gugnani MK, Pierson C, Vanderheide R, Girgis RE. Pulmonary edema complicating prostacyclin therapy in pulmonary hypertension associated with scleroderma: a case of pulmonary capillary hemangiomatosis. Arthritis Rheum. 2000;43(3):699-703.

38. McGuire F, Kennelly T, Tillack T, Robbins M. Pulmonary capillary hemangiomatosis associated with CREST syndrome: a case report and review of the literature. Respiration. 2010;80(5):435-438.

39. Kakkar N, Vasishta RK, Banerjee AK, Singh S, Kumar L. Pulmonary capillary haemangiomatosis as a cause of pulmonary hypertension in Takayasu's aortoarteritis. Respiration. 1997;64(5):381-383.

40. Moritani S, Ichihara S, Seki Y, Kataoka M, Yokoi T. Pulmonary capillary hemangiomatosis incidentally detected in a lobectomy specimen for a metastatic colon cancer. Pathol Int. 2006;56(6):350-357.

41. Domingo C, Encabo B, Roig J, López D, Morera J. Pulmonary capillary hemangiomatosis: report of a case and review of the literature. Respiration. 1992;59(3):178-180.

42. Lee C, Suh RD, Krishnam MS, et al. Recurrent pulmonary capillary hemangiomatosis after bilateral lung transplantation. JThorac Imaging. 2010;25(3):W89-W92.

43. de Perrot M, Waddell TK, Chamberlain D, Hutcheon M, Keshavjee S. De novo pulmonary capillary hemangiomatosis occurring rapidly after bilateral lung transplantation. J Heart Lung Transplant. 2003;22(6): 698-700.

44. Langleben D, Heneghan JM, Batten AP, et al. Familial pulmonary capillary hemangiomatosis resulting in primary pulmonary hypertension. Ann Intern Med. 1988;109(2):106-109.

45. Wirbelauer J, Hebestreit H, Marx A, Mark EJ, Speer CP. Familial pulmonary capillary hemangiomatosis early in life. Case Rep Pulmonol. 2011;2011:827591.

46. Donnelly N, Gorman AM, Gupta S, Samali A. The eIF2 $\alpha$ kinases: their structures and functions. Cell Mol Life Sci. 2013;70(19):3493-3511.

47. Berlanga JJ, Santoyo J, De Haro C. Characterization of a mammalian homolog of the GCN2 eukaryotic initiation factor 2alpha kinase. Eur J Biochem. 1999;265(2):754-762.

48. Zhang P, McGrath BC, Reinert J, et al. The GCN2 eIF2alpha kinase is required for adaptation to amino acid deprivation in mice. $\mathrm{Mol} \mathrm{Cell}$ Biol. 2002;22(19):6681-6688.

49. Anthony TG, McDaniel BJ, Byerley RL, et al. Preservation of liver protein synthesis during dietary leucine deprivation occurs at the expense of skeletal muscle mass in mice deleted for eIF2 kinase GCN2. J Biol Chem. 2004;279(35):36553-36561.

50. Castilho BA, Shanmugam R, Silva RC, Ramesh R, Himme BM, Sattlegger E. Keeping the eIF2 alpha kinase Gcn2 in check. Biochim Biophys Acta. 2014;1843(9):1948-1968.

51. Barrios-Rodiles M, Brown KR, Ozdamar B, et al. High-throughput mapping of a dynamic signaling network in mammalian cells. Science. 2005;307(5715):1621-1625.

52. Vattem KM, Wek RC. Reinitiation involving upstream ORFs regulates ATF4 mRNA translation in mammalian cells. Proc Natl Acad Sci USA. 2004;101(31):11269-11274. 
53. Carraro V, Maurin AC, Lambert-Langlais S, et al. Amino acid availability controls TRB3 transcription in liver through the GCN2/eIF2 $\alpha$ / ATF4 pathway. PLoS One. 2010;5(12):e15716.

54. Chan MC, Nguyen PH, Davis BN, et al. A novel regulatory mechanism of the bone morphogenetic protein (BMP) signaling pathway involving the carboxyl-terminal tail domain of BMP type II receptor. Mol Cell Biol. 2007;27(16):5776-5789.

55. Tong L, Heim RA, Wu S. Nitric oxide: a regulator of eukaryotic initiation factor 2 kinases. Free Radic Biol Med. 2011;50(12):1717-1725.

56. Lu W, Laszlo CF, Miao Z, Chen $\mathrm{H}$, Wu S. The role of nitric-oxide synthase in the regulation of UVB light-induced phosphorylation of the alpha subunit of eukaryotic initiation factor 2. J Biol Chem. 2009; 284(36):24281-24288.

57. Giaid A, Saleh D. Reduced expression of endothelial nitric oxide synthase in the lungs of patients with pulmonary hypertension. $N$ Engl $J$ Med. 1995;333(4):214-221.

58. Alvarez DF, Huang L, King JA, ElZarrad MK, Yoder MC, Stevens T. Lung microvascular endothelium is enriched with progenitor cells that exhibit vasculogenic capacity. Am J Physiol Lung Cell Mol Physiol. 2008;294(3):L419-L430.

59. Gallinetti J, Harputlugil E, Mitchell JR. Amino acid sensing in dietaryrestriction-mediated longevity: roles of signal-transducing kinases GCN2 and TOR. Biochem J. 2013;449(1):1-10.

60. Kubota H, Obata T, Ota K, Sasaki T, Ito T. Rapamycin-induced translational derepression of GCN4 mRNA involves a novel mechanism for activation of the eIF2 alpha kinase GCN2. J Biol Chem. 2003;278(23): 20457-20460.

61. Cherkasova VA, Hinnebusch AG. Translational control by TOR and TAP42 through dephosphorylation of eIF2alpha kinase GCN2. Genes Dev. 2003;17(7):859-872.

62. Proud CG. mTOR-mediated regulation of translation factors by amino acids. Biochem Biophys Res Commun. 2004;313(2):429-436.

63. Goncharova EA. mTOR and vascular remodeling in lung diseases: current challenges and therapeutic prospects. FASEB J. 2013;27(5): 1796-1807.

64. Goncharov DA, Kudryashova TV, Ziai H, et al. Mammalian target of rapamycin complex 2 (mTORC2) coordinates pulmonary artery smooth muscle cell metabolism, proliferation, and survival in pulmonary arterial hypertension. Circulation. 2014;129(8):864-874.

65. Iwanaga K, Yang Y, Raso MG, et al. Pten inactivation accelerates oncogenic K-ras-initiated tumorigenesis in a mouse model of lung cancer. Cancer Res. 2008;68(4):1119-1127.

66. Vaillancourt M, Ruffenach G, Meloche J, Bonnet S. Adaptation and remodeling of the pulmonary circulation in pulmonary hypertension. Can J Cardiol. 2015;31(4):407-415.

67. Won S, Eidenschenk C, Arnold CN, et al. Increased susceptibility to DNA virus infection in mice with a GCN2 mutation. JVirol. 2012;86(3): 1802-1808.

68. White CW, Sondheimer HM, Crouch EC, Wilson H, Fan LL. Treatment of pulmonary hemangiomatosis with recombinant interferon alpha-2a. N Engl J Med. 1989;320(18):1197-1200.
69. Koromilas AE. Roles of the translation initiation factor eIF2 $\alpha$ serine 51 phosphorylation in cancer formation and treatment. Biochim Biophys Acta. 2015 July; 1849(7):871-880.

70. Méndez-Lucas A, Hyroššová P, Novellasdemunt L, Viñals F, Perales JC. Mitochondrial phosphoenolpyruvate carboxykinase (PEPCK-M) is a pro-survival, endoplasmic reticulum (ER) stress response gene involved in tumor cell adaptation to nutrient availability. $J$ Biol Chem. 2014;289(32):22090-22102.

71. Ye J, Kumanova M, Hart LS, et al. The GCN2-ATF4 pathway is critical for tumour cell survival and proliferation in response to nutrient deprivation. EMBO J. 2010;29(12):2082-2096.

72. Singleton DC, Harris AL. Targeting the ATF4 pathway in cancer therapy. Expert Opin Ther Targets. 2012;16(12):1189-1202.

73. Wang Y, Ning Y, Alam GN, et al. Amino acid deprivation promotes tumor angiogenesis through the GCN2/ATF4 pathway. Neoplasia. 2013;15(8):989-997.

74. Trip P, Girerd B, Bogaard HJ, et al. Diffusion capacity and BMPR2 mutations in pulmonary arterial hypertension. Eur Respir J. 2014;43(4): 1195-1198.

75. Ogawa A, Miyaji K, Yamadori I, et al. Safety and efficacy of epoprostenol therapy in pulmonary veno-occlusive disease and pulmonary capillary hemangiomatosis. Circ J. 2012;76(7):1729-1736.

76. Kawut SM, Assaad AM, Arcasoy SM, Rosenzweig EB, Sonett JR, Borczuk AC. Pulmonary capillary hemangiomatosis: results of gene expression analysis. Chest. 2005;128(6 Suppl):575S-5766S.

77. Nayyar D, Muthiah K, Kumarasinghe G, et al. Imatinib for the treatment of pulmonary arterial hypertension and pulmonary capillary hemangiomatosis. Pulm Circ. 2014;4(2):342-345.

78. Adachi S, Hirashiki A, Kondo T, et al. Imatinib is partially effective for the treatment of pulmonary capillary hemangiomatosis. Intern Med. 2014;53(6):603-607.

79. Ginns LC, Roberts DH, Mark EJ, Brusch JL, Marler JJ. Pulmonary capillary hemangiomatosis with atypical endotheliomatosis: successful antiangiogenic therapy with doxycycline. Chest. 2003;124(5): 2017-2022.

80. Granstein RD, Murphy GF, Margolis RJ, Byrne MH, Amento EP. Gamma-interferon inhibits collagen synthesis in vivo in the mouse. J Clin Invest. 1987;79(4):1254-1258.

81. Brouty-Boyé D, Zetter BR. Inhibition of cell motility by interferon. Science. 1980;208(4443):516-518.

82. Eldor A, Fridman R, Vlodavsky I, Hy-Am E, Fuks Z, Panet A. Interferon enhances prostacyclin production by cultured vascular endothelial cells. J Clin Invest. 1984;73(1):251-257.

83. Dianzani F. Biological basis for the clinical use of interferon. Gut. 1993;34(Suppl 2):S74-S76.

84. White CW. Treatment of hemangiomatosis with recombinant interferon alfa. Semin Hematol. 1990;27(Suppl 4):S15-S22.

85. White CW, Wolf SJ, Korones DN, Sondheimer HM, Tosi MF, Yu A. Treatment of childhood angiomatous diseases with recombinant interferon alfa-2a. J Pediatr. 1991;118(1):59-66.
The Application of Clinical Genetics

\section{Publish your work in this journal}

The Application of Clinical Genetics is an international, peer-reviewed open access journal that welcomes laboratory and clinical findings in the field of human genetics. Specific topics include: Population genetics; Functional genetics; Natural history of genetic disease; Management of genetic disease; Mechanisms of genetic disease; Counseling and ethical

\section{Dovepress}

issues; Animal models; Pharmacogenetics; Prenatal diagnosis; Dysmorphology. The manuscript management system is completely online and includes a very quick and fair peer-review system, which is all easy to use. Visit http://www.dovepress.com/testimonials.php to read real quotes from published authors. 